\title{
Active Source Current Filtering to Minimize the DC-Link Capacitor in Switched Reluctance Drives
}

\author{
Annegret Klein-Hessling, Bernhard Burkhart, and Rik W. De Doncker
}

\begin{abstract}
Switched reluctance machines receive increased attention from the automotive industry because of their cost efficiency. However, the independent phase excitation and the resulting current reversal demand comparatively large dc-link capacitors to meet the requirements regarding the ripple on the dc-link voltage and current. This paper validates the effects of the usage of a dc-dc boost converter to reduce the size of the dc-link capacitor by actively filtering the source current. The active filter is compared with the state-of-the-art topology and a passive filter. The investigations show that the active filter is able to reduce the dc-link capacitance by $80 \%$. The dc-dc converter also provides the feature of adjusting the inverter dc-link voltage level independently from the battery voltage level. The positive effect of this additional degree of freedom on the machine efficiency is investigated and due to this feature the total efficiency of the electrical drive train remains nearly unchanged despite the extra losses in the dc-dc converter. All presented results are based on detailed simulations and experimentally validated with a $20 \mathrm{~kW}$ switched reluctance generator.
\end{abstract}

Index Terms-Active filters, converters, electric vehicles, reluctance generators, reluctance machines.

\section{INTRODUCTION}

$\mathrm{S}$ WITCHED reluctance machines (SRMs) are cost effective, robust and very reliable. All these characteristics are required in electric generators used, for example, in electric vehicle range extenders. However, one drawback of SRMs is the comparatively large dc-link capacitor needed to smoothen the dc-link voltage caused by the high amount of magnetization energy oscillating between the dc-link capacitor and the machine [1]-[3]. A high ripple on the dc-link voltage is unwanted and increases the risk of over-voltage across the semiconductors. Additionally, in cases where the dc-link capacitor is directly connected to a voltage source such as a battery, a ripple on the dc-link voltage leads to a large source current ripple. This current ripple produces ohmic losses in the internal resistance of the source. Experiments showed that a $20 \mathrm{~kW}-\mathrm{SRM}$ generator used as range extender for electric vehicles can cause extra losses in the battery that reach a few hundred watts [4]. The ripple increases even further if electric resonant frequencies of the system are excited by the frequency

\footnotetext{
Manuscript received June 18, 2018.

The authors are with the Institute for Power Electronics and Electrical Drives (ISEA), RWTH Aachen University, 52066 Aachen, Germany. (email: post@ isea.rwth-aachen.de)

Digital Object Identifier 10.24295/CPSSTPEA.2019.00007
}

components of the SRM voltage waveforms.

A large dc-link capacitor increases the size, weight and price of the SRM inverter compared to inverters for conventional rotating field drives that are based on induction or synchronous machines [5]. Recent publications recommend phase switching techniques to minimize the size of the dc-link capacitor [1], [2], [6]-[8]. These switching techniques are aimed at commutating the magnetization energy stored in one phase to the next active phase without buffering it in the dc-link capacitor. However, the switching techniques assume an overlap between the SRM phases. This assumption is only fulfilled by SRMs with at least three phases. Additionally, the current in the SRM still has to remain actively controllable. Therefore, these switching techniques are not applicable for two-phase SRMs and/or SRMs in single-pulse operation.

In [6]-[8], a passive input filter is proposed to reduce the ripple on the source current. The presented passive input filter consists of an inductance $L_{\mathrm{DC}}$ and a dc-link capacitor with the capacitance $C_{\mathrm{DC}}$. The active filter proposed in this paper is a bidirectional boost dc-dc converter. The dc-dc converter allows to actively control the current between the dc-link capacitor and the voltage source and, therefore, reduces the ripple on the source current. This filter topology is already applied for active power decoupling of single-phase systems [11]. However, this paper firstly proposed the application of the active filter to minimize the dc-link capacitor in switched reluctance drives.

Beside active filtering, the boost converter is able to eliminate the effects of the dc-link voltage level variation due to the battery state of charge (SOC) [9], [10]. The voltage of common $400 \mathrm{~V}$ automotive batteries in the discharged state is $100 \mathrm{~V}$ lower than that in the charged state [12]. On SRMs in single-pulse operation, this has a considerable effect on the machine efficiency [13].

\section{Active Filtering Using a DC-DC Converter}

Fig. 1 shows an equivalent circuit model of a two-phase SRM inverter connected to a battery via a cable. The battery is modeled as an ideal voltage source $u_{\text {bat }}$ and an internal resistance $R_{\mathrm{i}, \mathrm{bat}}$. The cable, which connects the battery to the inverter, is modeled as a serial connection of a resistance $R_{\text {cable }}$ and an inductance $L_{\text {cable }}$. The SRM inverter consists of a dc-link capacitance $C_{\mathrm{DC}}$ and two asymmetric half bridges with switches $\mathrm{S}_{1}, \mathrm{~S}_{2}$ and $\mathrm{S}_{3}, \mathrm{~S}_{4}$, respectively.

The two-phase current $i_{\mathrm{ph}}$ and the total SRM current $i_{\mathrm{SRM}}$ during single-pulse operation in generating mode [14] are shown in Fig. 1. The instantaneous total SRM current is positive 

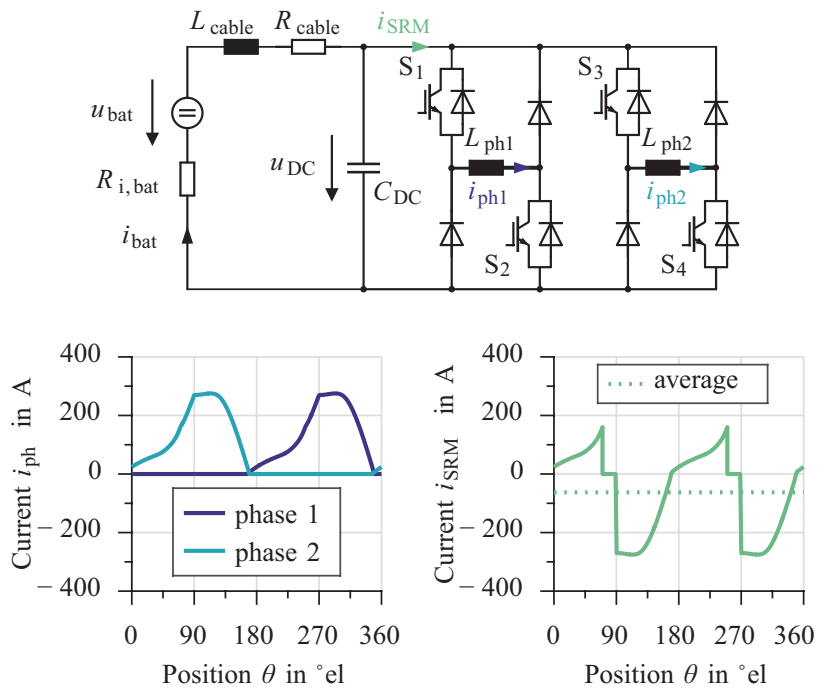

Fig. 1. Phase currents and total current of a two-phase SRM in generating mode.

TABLE I

PARAMETERS OF INVESTIGATED SRM

\begin{tabular}{llc}
\hline \hline Parameter & Variable & Value \\
\hline Number of phases & $N_{\mathrm{ph}}$ & 2 \\
Number of stator poles & $N_{\mathrm{s}}$ & 12 \\
Number of rotor poles & $N_{\mathrm{r}}$ & 6 \\
Rated dc-link voltage & $u_{\mathrm{DC}}$ & $300 \mathrm{~V}$ \\
Rated speed & $n_{\text {mech }}$ & $7500 \mathrm{rpm}$ \\
Rated power & $P_{\text {mech }}$ & $-20 \mathrm{~kW}$ \\
Outer core diameter & $d_{\mathrm{SRM}}$ & $220 \mathrm{~mm}$ \\
Stack length & $l_{\mathrm{SRM}}$ & $60 \mathrm{~mm}$ \\
Air gap length & $l_{\text {gap }}$ & $1 \mathrm{~mm}$ \\
\hline \hline
\end{tabular}

during magnetization, zero during freewheeling and negative during demagnetization of one phase. No overlap of the phase currents occurs due to the low number of SRM phases. The average total SRM current $\bar{i}_{\mathrm{SRM}}=-66.7 \mathrm{~A}$ is negative because of the generating mode of the SRM. The average current is superposed with a very high peak-to-peak ripple $(\approx 650 \%)$. The frequency of the oscillation is equal to the electric frequency of the SRM times the number of SRM phases.

The simulations presented in this paper are carried out using MATLAB Simulink [15] coupled with PLECS [16]. The SRM is modeled by look-up tables obtained from a stationary 2D finite element analysis (FEA) [17]. The parameters of the investigated SRM are given in Table I. The design of the SRM is investigated in detail in [4], [18]. The machine is designed for the automotive range extender application and, therefore, mainly operates in generator mode at a rated speed and power. However, due to the asymmetric rotor, the SRM is able to ramp up the combustion engine for starting.

An equivalent circuit model of the proposed active filter topology, battery, cable and SRM inverter is shown in Fig. 2. For simplification, only one SRM phase is depicted. The dc-dc converter consists of two switches $\mathrm{S}_{\mathrm{DC}, 1}$ and $\mathrm{S}_{\mathrm{DC}, 2}$, an inductance $L_{\mathrm{DC}}$ and an input capacitance $\mathrm{C}_{\mathrm{in}}$. The depicted dc-dc converter in Fig. 2 is a bidirectional boost converter with $u_{\mathrm{in}} \leq u_{\mathrm{DC}}$. Bidirectional

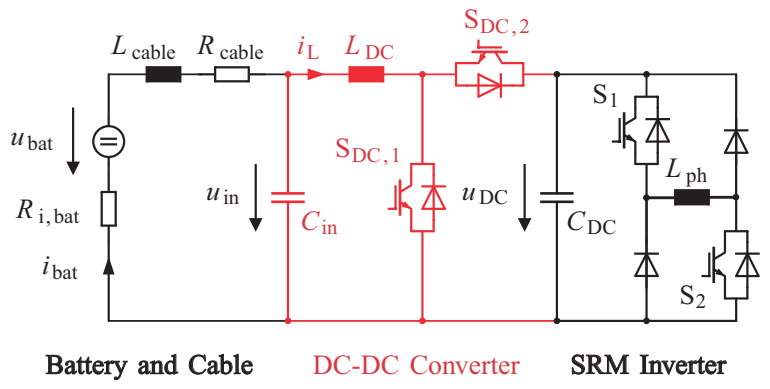

Fig. 2. Equivalent circuit of SRM with proposed active filter [13].

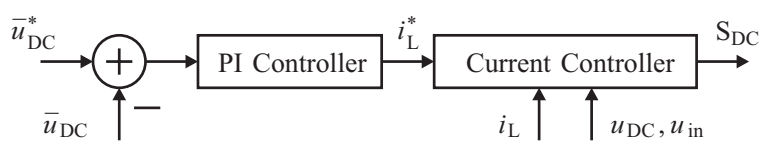

Fig. 3. Control of average dc-link voltage with active filter [13].

operation is required to operate the SRM as an integrated starter-generator (ISG), i.e., in motoring and generating mode ramp-up of the combustion engine and for nominal operation, respectively. If the SRM operates as a motor, the current through the inductor $\left(i_{\mathrm{L}}>0\right)$ is controlled by switch $\mathrm{S}_{\mathrm{DC}, 1}$. If the SRM operates as a generator, the current $\left(i_{\mathrm{L}}<0\right)$ is controlled by switch $\mathrm{S}_{\mathrm{DC}, 2}$.

\section{A. Control of Average DC-Link Voltage}

The aim of the boost converter is to supply the SRM inverter with a reference dc-link voltage $u_{\mathrm{DC}}^{*}$ and simultaneously filter the source current $i_{\text {bat }}$. Filtering the source current means holding the current through the inductor $i_{\mathrm{L}}$ at a nearly constant level and thereby ensuring a smooth battery current $i_{\text {bat }}$. This can be achieved by controlling the average dc-link voltage $\bar{u}_{\mathrm{DC}}$ instead of the instantaneous dc-link voltage $u_{\mathrm{DC}}$. In a stationary operating point, this results in a ripple on the dc-link voltage with a frequency that is equal to the electric frequency of the SRM times the number of SRM phases.

The average dc-link voltage controller is shown in Fig. 3. At the beginning of each voltage period, the average reference dc-link voltage $\bar{u}_{\mathrm{DC}}^{*}$ is compared with the actual average voltage $\bar{u}_{\mathrm{DC}}$ of the last period. The difference is fed to a PI controller, which provides the reference value for the inductor current $i_{\mathrm{L}}^{*}$. Afterwards, a current controller determines the switching signals for the boost converter.

The current through the inductor is controlled with pulsewidth modulation (PWM). The duty cycle $d$ has to be calculated before each PWM period $T$. The current through an inductor is determined by the integration of the inductor voltage $u_{\mathrm{L}}$ divided by its inductance:

$$
i_{\mathrm{L}}(t)=i_{\mathrm{L}}\left(t_{0}\right)+\frac{1}{L_{\mathrm{DC}}} \int_{t_{0}}^{t} u_{\mathrm{L}}(\tau) \mathrm{d} \tau
$$

As mentioned before, only one switch of the bidirectional 


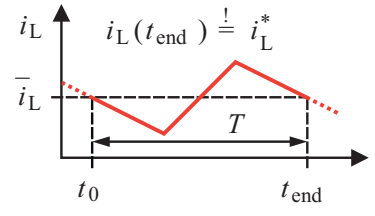

(a) $\mathrm{CCM}, i_{\mathrm{L}}\left(t_{\text {end }}\right)=\bar{i}_{\mathrm{L}}$

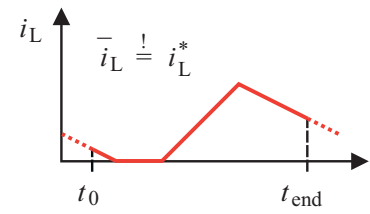

(c) $\mathrm{DCM}, i_{\mathrm{L}}\left(t_{\text {end }}\right) \neq 0$

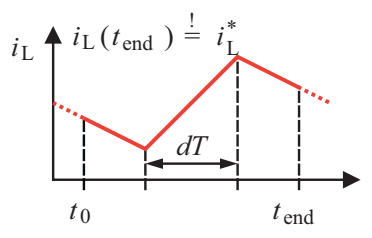

(b) $\mathrm{CCM}, i_{\mathrm{L}}\left(t_{\text {end }}\right) \neq \bar{i}_{\mathrm{L}}$

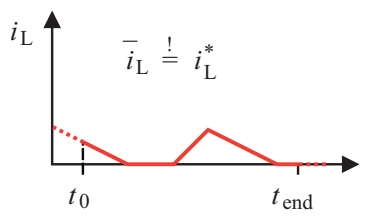

(d) DCM, $i_{\mathrm{L}}\left(t_{\text {end }}\right)=0$
Fig. 4. Different cases of the predictive PWM-based current controller.

dc-dc converter is controlled in each switching period. For a positive reference current $i_{\mathrm{L}}^{*}$, the duty cycle is applied to $\mathrm{S}_{\mathrm{DC}, 1}$. Vice versa, in the case of a negative current, switch $\mathrm{S}_{\mathrm{DC}, 2}$ is used. Therefore, the voltage $u_{\mathrm{on}}$ applied to the inductor during the switch conduction interval of the period depends on which switch is used:

$$
u_{\mathrm{on}}= \begin{cases}u_{\mathrm{in}} & i_{\mathrm{L}}^{*}>0 \\ u_{\mathrm{in}}-u_{\mathrm{DC}} & \text { else. }\end{cases}
$$

When the switches are open, the current conducts through the diodes. Depending on the sign of the current, the applied inductor voltage $u_{\text {off }}$ is determined by:

$$
u_{\mathrm{off}}= \begin{cases}u_{\mathrm{in}} & i_{\mathrm{L}}^{*}<0 \\ u_{\mathrm{in}}-u_{\mathrm{DC}} & \text { else. }\end{cases}
$$

In the case of $i_{\mathrm{L}}^{*}=0$, both switches are open and no duty cycle is calculated. Assuming constant voltages $u_{\mathrm{DC}}$ and $u_{\mathrm{in}}$, the current at the end of a PWM period $t_{\text {end }}$ can be predicted from the quantities at the beginning of the PWM period $t_{0}$ :

$$
i_{\mathrm{L}}\left(t_{\text {end }}\right) \approx i_{\mathrm{L}}\left(t_{0}\right)+\frac{d T}{L_{\mathrm{DC}}} u_{\text {on }}\left(t_{0}\right)+\frac{(1-d) T}{L_{\mathrm{DC}}} u_{\text {off }}\left(t_{0}\right)
$$

For simplification, voltage drops across the switches and diodes are not considered in the shown equations. However, they can be easily considered in the controller implementation. The duty cycle for the next PWM step can be determined by solving (4) for $d$ depending on $i_{\mathrm{L}}\left(t_{\text {end }}\right)$. If center aligned PWM is assumed, four different cases have to be distinguished (Fig. 4):

\section{(1) Steady State Continuous Conduction Mode (CCM)}

SRM, dc-dc converter and its controller are in steady state. Therefore, the current reference $i_{\mathrm{L}}^{*}$ is the same as that of the previous PWM period. If $i_{\mathrm{L}}\left(t_{\text {end }}\right)=i_{\mathrm{L}}^{*}$ is applied to (4), the average current $\bar{i}_{\mathrm{L}}$ is equal to the reference current $i_{\mathrm{L}}^{*}$ (Fig. 4(a)). The duty cycle is calculated by:

$$
d_{\mathrm{CCM}}=\frac{\left(i_{\mathrm{L}}^{*}-i_{\mathrm{L}}\left(t_{0}\right)\right) L_{\mathrm{DC}} / T-u_{\mathrm{off}}\left(t_{0}\right)}{u_{\mathrm{on}}\left(t_{0}\right)-u_{\mathrm{off}}\left(t_{0}\right)}
$$

\section{(2) Transient Continuous Conduction Mode (CCM)}

In this case, the current reference $i_{\mathrm{L}}^{*}$ has changed compared to the previous PWM period. As shown in Fig. 4(b), value $i_{\mathrm{L}}\left(t_{0}\right)$ is not yet equal to $i_{\mathrm{L}}^{*}$. To achieve steady state operation in the next PWM step, $i_{\mathrm{L}}\left(t_{\text {end }}\right)=i_{\mathrm{L}}^{*}$ is applied, resulting in the same duty cycle $d_{\mathrm{CCM}}$ as in (5). Due to the control of the average dc-link voltage, the current reference changes only at the first PWM step of the dclink voltage averaging period. The averaging frequency is the electric frequency $f_{\mathrm{el}}$ of the SRM times the number of SRM phases $N_{\mathrm{ph}}$. If $f_{\mathrm{el}} \cdot N_{\mathrm{ph}}<<f_{\mathrm{PWM}}=1 / T$, the average deviation from the reference current is negligible.

\section{(3) Discontinuous Conduction Mode With $i_{\mathrm{L}}\left(t_{\text {end }}\right) \neq 0$}

If the absolute current reference $\left|i_{\mathrm{L}}^{*}\right|$ becomes too small, the dc-dc converter has to change to discontinuous conduction mode (DCM). This is the case if the SRM operates in partial load. A control of $i_{\mathrm{L}}\left(t_{\text {end }}\right)=i_{\mathrm{L}}^{*}$ does not result in $\bar{i}_{\mathrm{L}}=i_{\mathrm{L}}^{*}$ anymore. With (4), the average current in dependence on the duty cycle $d$ has to be calculated and resolved for $d$. Additionally, the interval in which the current is zero has to be considered. The resulting duty cycle is:

$$
\begin{aligned}
& d_{\mathrm{DCM}, 1}=\frac{-b \pm \sqrt{b^{2}-4 a c}}{2 a T} \\
\text { with } \quad a & =\frac{u_{\mathrm{off}}\left(t_{0}\right)}{8 L_{\mathrm{DC}}} \\
b & =\frac{T}{4 L_{\mathrm{DC}}}\left(2 u_{\mathrm{on}}\left(t_{0}\right)-u_{\mathrm{off}}\left(t_{0}\right)\right) \\
c & =\frac{u_{\mathrm{off}}\left(t_{0}\right) T^{2}}{8 L_{\mathrm{DC}}}-\frac{i_{\mathrm{L}}^{2}\left(t_{0}\right) L_{\mathrm{DC}}}{2 u_{\text {off }}\left(t_{0}\right)}-i_{\mathrm{L}}^{*} T
\end{aligned}
$$

\section{(4) Discontinuous Conduction Mode With $i_{\mathrm{L}}\left(t_{\text {end }}\right)=0$}

For very small current reference, the current at the end of the PWM period becomes zero. As in case (3), the average current $\bar{i}_{\mathrm{L}}=i_{\mathrm{L}}^{*}$ is controlled. Due to $i_{\mathrm{L}}\left(t_{\text {end }}\right)=0$, the duty cycle is calculated by:

$$
d_{\mathrm{DCM}, 2}=\frac{1}{T} \sqrt{\frac{\frac{i_{\mathrm{L}}^{2}\left(t_{0}\right) L_{\mathrm{DC}}^{2}}{u_{\mathrm{off}}\left(t_{0}\right)}+2 L_{\mathrm{DC}}{ }^{2} i_{\mathrm{L}}^{*} T}{u_{\mathrm{on}}\left(t_{0}\right)-u_{\mathrm{on}}^{2}\left(t_{0}\right) / u_{\mathrm{off}}\left(t_{0}\right)}}
$$

To reduce the current through the inductor and increase the effective total switching frequency, it is possible to use a multiphase dc-dc converter [19]. The multi-phase dc-dc converter 


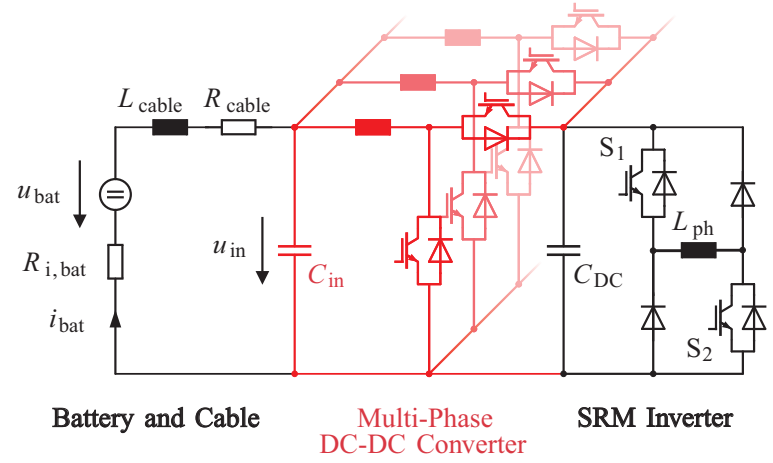

Fig. 5. Equivalent circuit of active filter with multi-phase dc-dc converter.
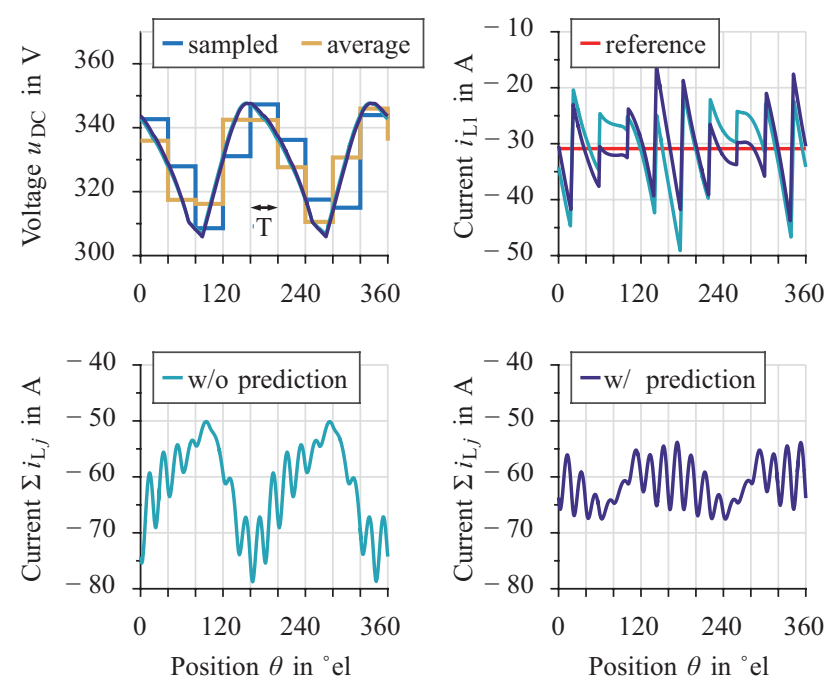

Fig. 6. Difference between sampled and predicted average dc-link voltage control.

consists of multiple single dc-dc converters connected in parallel as depicted in Fig. 5. For interleaved operation of the multi-phase dc-dc converter with $N_{\mathrm{DC}}$ parallel phases, the PWM signals of each converter leg $j$ are phase shifted by $j T / N_{\mathrm{DC}}$ so that the resulting effective switching frequency of the converter is a multiple of the switching frequency of a single phase.

The usage of the measured voltages $u_{\mathrm{in}}\left(t_{0}\right)$ and $u_{\mathrm{DC}}\left(t_{0}\right)$ at the beginning of the actual PWM step in (4) is a simplification. It assumes that the voltages between two PWM steps do not vary. This does not necessarily apply to the dc-link voltage. The difference between $u_{\mathrm{DC}}\left(t_{0}\right)$ and $u_{\mathrm{DC}}\left(t_{\text {end }}\right)$ depends on capacitance $C_{\mathrm{DC}}$ and the dc-dc converter switching frequency $f_{\mathrm{PWM}}=1 / T$. A better approach is the usage of the average dc-link voltage during one PWM period (Fig. 6). This average voltage is not measurable at the beginning of a PWM period when the duty cycle has to be calculated.

The voltage of a capacitor is described by the integration of its current:

$$
u_{\mathrm{DC}}(t)=u_{\mathrm{DC}}\left(t_{0}\right)+\frac{1}{C_{\mathrm{DC}}} \int_{t_{0}}^{t} i_{\mathrm{DC}}(\tau) \mathrm{d} \tau
$$

To calculate the dc-link voltage at the end of each PWM step,

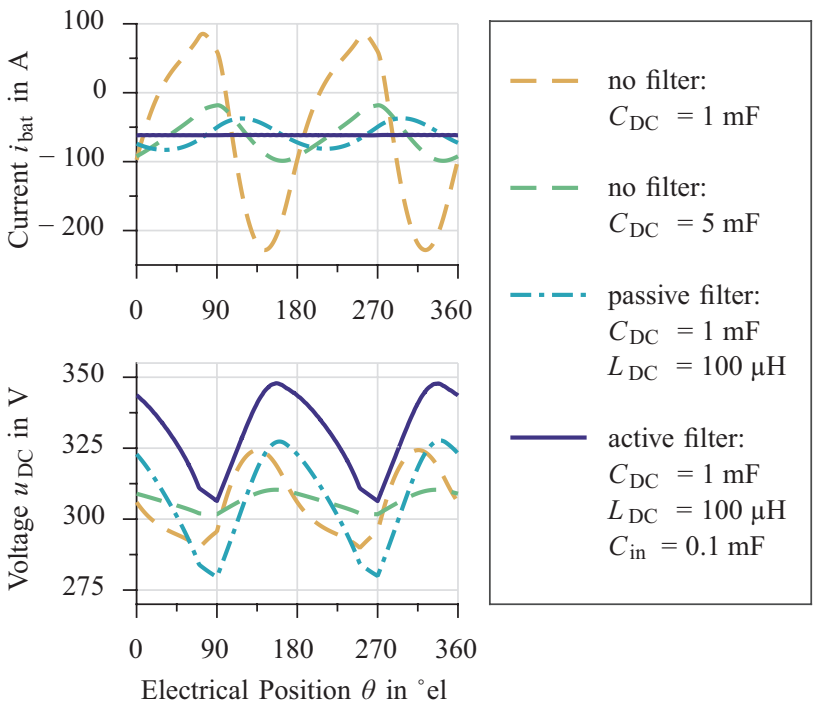

Fig. 7. Influence of different filters on source current and dc-link voltage at mechanical input power $P_{\text {mech }}=-20 \mathrm{~kW}$ and speed $n=7500 \mathrm{rpm}$.

this equation is simplified to:

$$
u_{\mathrm{DC}}\left(t_{\text {end }}\right) \approx u_{\mathrm{DC}}\left(t_{0}\right)+\frac{i_{\mathrm{DC}}\left(t_{0}\right) T}{C_{\mathrm{DC}}}
$$

whereas $i_{\mathrm{DC}}\left(t_{0}\right)=i_{\mathrm{L}}^{*}-i_{\mathrm{SRM}}\left(t_{0}\right)$ is the average current in the dc-link capacitor during one PWM period. To improve the PWM current controller, the predicted average voltage $1 / 2 u_{\mathrm{DC}}\left(t_{0}\right)+1 / 2 u_{\mathrm{DC}}\left(t_{\text {end }}\right)$ within the PWM step is calculated and used instead of the $u_{\mathrm{DC}}\left(t_{0}\right)$ in (2)-(7).

Fig. 6 shows simulation results of the dc-link voltage, the current through one inductor $i_{\mathrm{L} 1}$ of a two-phase dc-dc converter and the sum of both inductor currents $\Sigma i_{\mathrm{L} j}$. The switching frequency is $f_{\text {PWM }}=15 \mathrm{kHz}$. The approach without prediction uses the sampled dc-link voltage at $t_{0}$. The other approach uses the predicted average dc-link voltage. In particular, at the minimal dc-link voltage, the approach without prediction is not able to control the current through the inductor to its reference value. This results in an oscillation on $\Sigma i_{\mathrm{L} j}$. The oscillation has the same frequency as the dc-link voltage oscillation. The approach with prediction is able to eliminate this oscillation. Only the ripple due to the switching frequency has to be smoothened by the input capacitor $C_{\mathrm{in}}$.

\section{B. Filter Topology Comparison}

The state-of-the-art approach to smoothen the $i_{\mathrm{SRM}}$-oscillation is a conventional dc-link capacitor (Fig. 1). The resulting battery current $i_{\text {bat }}$ and the dc-link voltage $u_{\mathrm{DC}}$ for the rated operating point of the SRM are shown in Fig. 7. The figure depicts the simulation results for two dc-link configurations: reduced capacitance $\left(C_{\mathrm{DC}}=1 \mathrm{mF}\right)$ and required capacitance to avoid battery current reversal $\left(C_{\mathrm{DC}}=5 \mathrm{mF}\right)$.

Fig. 7 shows that only the larger dc-link capacitance suppresses the battery current reversal. However, the peak-topeak ripple on the current is still around $120 \%$ of the average 
current. With the smaller dc-link capacitance the ripple reaches around $470 \%$.

The resulting battery current and dc-link voltage for a onephase boost converter with $f_{\mathrm{PWM}}=40 \mathrm{kHz}$ switching frequency used as active filter are also shown in Fig. 7. The ripple on the source current is completely eliminated and the battery is charged with a dc current.

The passive input filter presented in [6]-[8] is included in the comparison in Fig. 7. The passive input filter consists only of an inductance $L_{\mathrm{DC}}$ and a dc-link capacitance $C_{\mathrm{DC}}$. It does not have switches as the active filter. The passive filter with $C_{\mathrm{DC}}=1 \mathrm{mF}$ is able to reduce more current ripple than a $5 \mathrm{mF}$-dc-link capacitance without any filter.

The comparison of the dc-link voltages shows that only the topology with large capacitance reduces the ripple to about $4 \%$ of the average voltage $\bar{u}_{\mathrm{DC}}=310 \mathrm{~V}$. All topologies with a dclink capacitance of $C_{\mathrm{DC}}=1 \mathrm{mF}$ experience a similar voltage ripple of approximately $20 \%$. Due to the two-phase SRM, the voltage ripple appears twice per electric period. The dc-link voltage ripple has a minor influence on the SRM behavior. Due to the higher voltage at the unaligned position $\left(\theta=180^{\circ} \mathrm{el}\right)$, the phase can be magnetized a little faster.

Since the active filter is a dc-dc boost converter, the average dc-link voltage of the active filter $\left(\bar{u}_{\mathrm{DC}}=335 \mathrm{~V}\right)$ is higher than the voltage in other topologies. The filter characteristic of the dc-dc converter is applicable if $u_{\mathrm{DC}}>u_{\mathrm{in}}$. Otherwise, the diode of switch $S_{\mathrm{DC}, 1}$ conducts and the current $i_{\mathrm{L}}$ is no longer actively controllable. The influence of the average dc-link voltage level on the SRM behavior will be discussed in Section III-A.

The passive filter is designed for one specific operating point. In this paper, for a better comparison between the topologies, the passive filter is designed for the rated operating point of the investigated SRM. In [6]-[8], a design for the 'worst case' operating point is recommended. For the observed SRM in this paper, this operating point would be at a low speed and rated torque. A design for this operating point results again in a large capacitance $(>5 \mathrm{mF})$ or a large inductance $(>1 \mathrm{mH})$. A large inductance limits the dynamic behavior of the SRM, e.g., during ramp-up. Fast changes of the SRM torque are no longer possible because of the slower current gradient $\left(\mathrm{d} i_{\mathrm{L}} / \mathrm{d} t \sim 1 / L_{\mathrm{DC}}\right)$.

A comparison of the resulting battery current $i_{\text {bat }}$ and the dclink voltage $u_{\mathrm{DC}}$ for two different speeds (rated speed and half rated speed) with a passive and an active filter is displayed in Fig. 8. The mechanical input torque of the switched reluctance generator is kept constant for all operating points at a rated torque of $-25.5 \mathrm{Nm}$, resulting in a mechanical input power of $-10 \mathrm{~kW}$ and $-20 \mathrm{~kW}$, respectively. It can be seen, that in the case of the passive filter, the current ripple increases with decreasing speed. At $3750 \mathrm{rpm}$, the peak current reaches up to $60 \mathrm{~A}$, i.e., the peak-to-peak ripple is about $200 \%$ of the average battery current.

With the active filter, different operating points have no influence on the battery current ripple. The battery current is kept constant for both speeds. In addition, the dc-link voltage ripple is affected more for the passive filter at a low speed. The investigation shows the major advantages of the active filter compared to the passive filter. Its behavior and filter capability

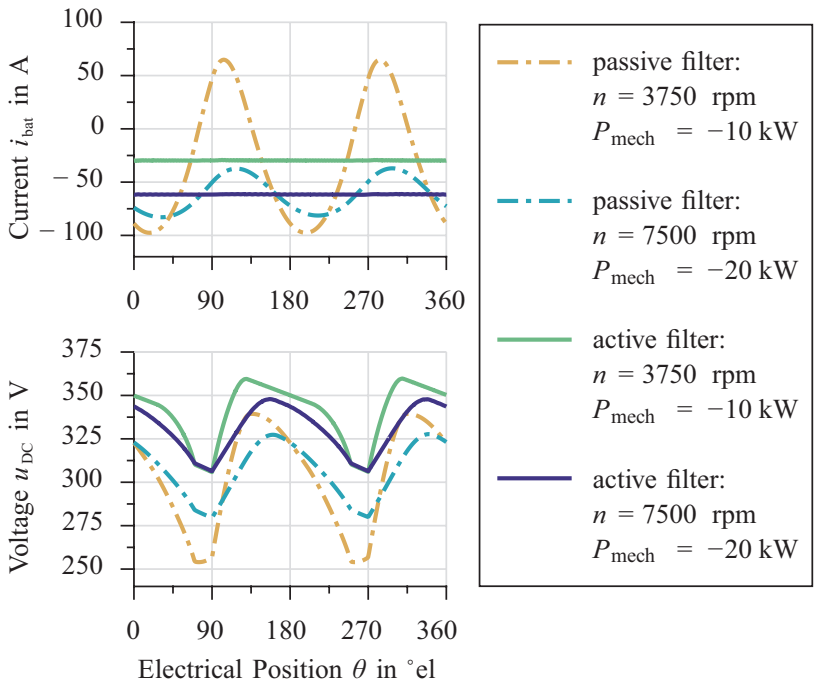

Fig. 8. Influence of speed on the operation of the range extender using active and passive current filter at a rated torque of $-25.5 \mathrm{Nm}$.

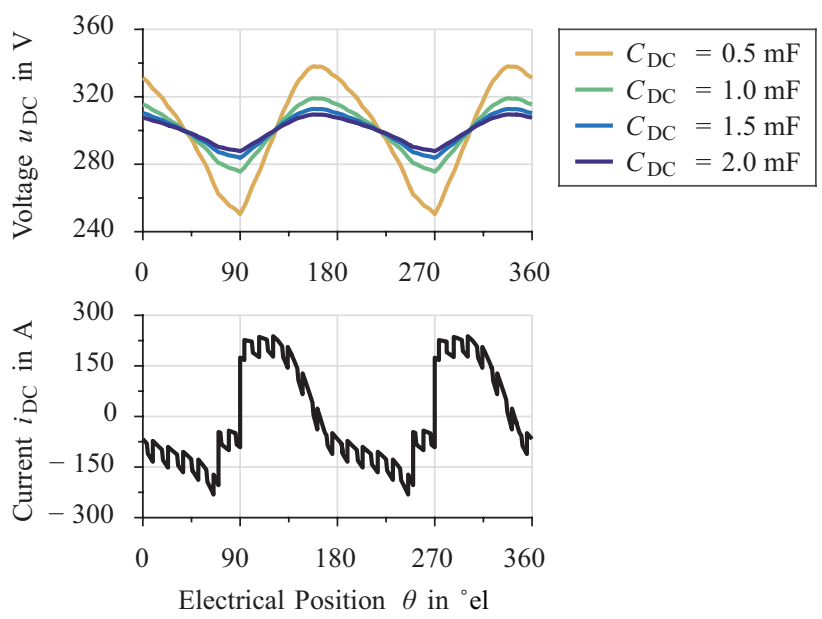

Fig. 9. Effect of different dc-link capacitances on dc-link voltage $u_{\mathrm{DC}}$ and capacitor current $i_{\mathrm{DC}}$

are independent of the SRM operating point.

\section{DC-Link Capacitance Minimization}

The main purpose of the dc-dc boost converter is the reduction of the dc-link capacitance by actively filtering the SRM dc power. The dc-link capacitance $C_{\mathrm{DC}}$ does not directly affect the filtering capability. Only the dc-link voltage oscillation and, therefore, the converter control are affected by the dc-link capacitance. The effect is investigated in Fig. 9 for the rated operating point and a battery voltage of $u_{\text {bat }}=250 \mathrm{~V}$. The dc-link voltage $u_{\mathrm{DC}}$ and the capacitor current $i_{\mathrm{DC}}$ are shown.

The capacitor current is not affected by the capacitance $C_{\mathrm{DC}}$. The capacitor current is the difference of the total SRM current $i_{\mathrm{SRM}}$ and the current through the diode or switch $\mathrm{S}_{\mathrm{DC}, 2}$. The dclink voltage ripple amplitude has an anti-proportional relation to the capacitance. In the converter design, the voltage ripple needs to be limited to avoid the risk of over-voltage across the semiconductors. In addition, the boost converter is only able to 


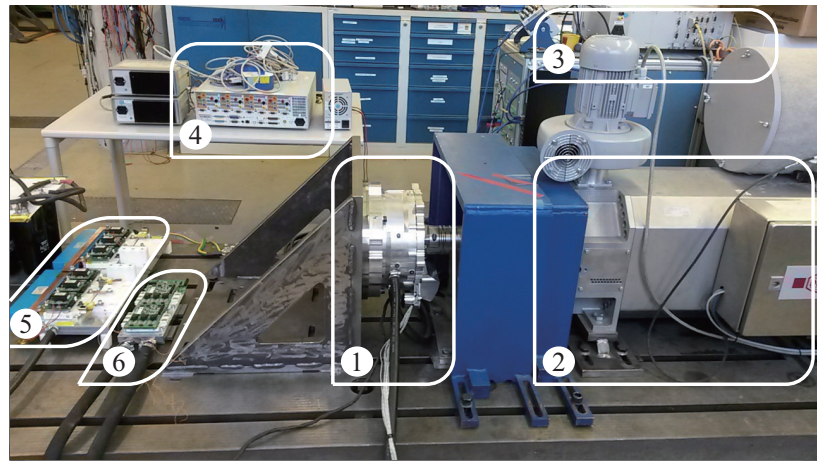

Fig. 10. Test bench setup: (1) SRM. (2) Load machine (IM). (3) Torque and speed probe unit. (4) Electrical power analyzer. (5) SRM inverter with integrated dc-dc converter switches. (6) DC-DC converter inductors.

apply its filter capability if the dc-link voltage is larger than the input voltage. The dc-link capacitance for the inverter is chosen to be $C_{\mathrm{DC}}=1 \mathrm{mF}$. This is a reduction by $80 \%$ compared to the capacitance required by the state-of-the-art topology without the filter to avoid battery current reversal $\left(C_{\mathrm{DC}}=5 \mathrm{mF}\right)$.

The capacitor losses $P_{\mathrm{C}}$ can be separated into dielectric losses and ohmic losses [20]. Dielectric losses are mainly determined by the product of capacitance and peak-to-peak voltage ripple. As the dc-link voltage ripple is anti-proportional to the capacitance, the product remains constantly independent of the dc-link capacitance. The ohmic capacitor losses are affected by the rms inductor current. The inductor current remains constant for all capacitance variations. Therefore, the capacitor losses do not depend on the capacitance. The capacitor losses for the built-up capacitor are approximately $P_{\mathrm{C}} \approx 6.7 \mathrm{~W}$ in the rated operating point of the investigated SRM. The losses are small compared to the inductor and semiconductor losses and are neglected in the following.

\section{Measurement Results and Validation}

The proposed active filter is validated by measurements on a test bench for electrical drives. The parameters of the range extender SRM [4] are the same as investigated in the simulations in the previous section. The investigations focus on the rated operating point due to the range extender application. Especially, the internal combustion engine experiences a large efficiency drop under partial load operation. The SRM inverter consists of four half bridges of two B6-IGBT-modules (HybridPACK 2, Infineon [21]). The two unused phase legs of the B6-modules are used for a two-phase dc-dc converter. Each inductor is designed for an inductance $L_{\mathrm{DC}}=214 \mu \mathrm{H}$. The input capacitance is $C_{\text {in }}=330 \mu \mathrm{F}$ and the dc-link capacitance $C_{\mathrm{DC}}=1 \mathrm{mF}$.

A picture of the test bench setup is presented in Fig. 10. It shows the SRM inverter and the inductors of the dc-dc converter including printed circuit boards (PCBs) for voltage and current measurements. Due to the dc-dc converter, the capacitance is reduced by $80 \%$ (Section II-B). This leads to a volume and weight reduction of the drive system, as the capacitor weight and volume are proportional to the capacitance. Fig. 10 shows that the minimized capacitor (blue rectangle) is approximately

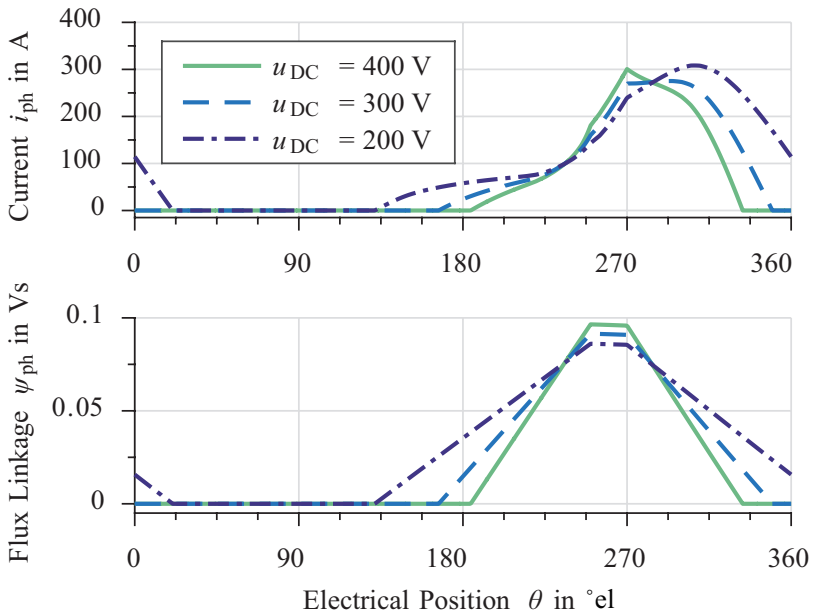

Fig. 11. Phase current and flux-linkage trajectories for different dc-link voltages at mechanical input power $P_{\text {mech }}=-20 \mathrm{~kW}$ and $7500 \mathrm{rpm}$.

the same volume as the additional components due to the dc$\mathrm{dc}$ converter. This results in a volume reduction by $60 \%$ of the proposed power electronic topology compared to the state-ofthe-art topology without the filter.

\section{A. Influence of DC-Link Voltage on SRM}

Apart from filtering the source current, the dc-dc converter can be used to adjust the dc-link voltage level. The average dclink voltage has an influence on the phase current $i_{\mathrm{ph}}$ and the phase-flux linkage $\psi_{\text {ph }}$ of the SRM. Both values are important for the losses occurring in the SRM and, therefore, the efficiency of the drive system.

Fig. 11 shows the effect of the different dc-link voltages on the trajectories of the phase current and phase flux-linkage for one electrical period at the rated operating point (7500 rpm, $-20 \mathrm{~kW})$. The SRM is designed for a battery with a rated voltage of $300 \mathrm{~V}$. The minimum voltage at a low SOC level is assumed to be $200 \mathrm{~V}$. $400 \mathrm{~V}$ is assumed to be the maximum boosted voltage. Each operating point is optimized for the best efficiency as presented in [22]. The gradient of the flux-linkage is proportional to the dc-link voltage. Therefore, the conduction time per period increases with decreasing dc-link voltages. The efficiency optimization of the control parameters results in an increased free-wheeling time with increasing dc-link voltages. The peak value of the phase currents remains nearly constant for different voltage levels. The rms value of the phase current, however, increases for decreased dc-link voltages, as a longer conduction time is required.

The SRM losses are measured on a test bench as well as simulated by a coupled 2D-FEA simulation using MATLAB Simulink [15] and FLUX 2D [17]. On the test bench, the mechanical power is measured with a torque and speed probe [23]. The electrical powers are determined by current and voltage probes [24], [25] at the terminals of the SRM and at the dc terminals. The SRM losses and the inverter losses are calculated from the difference of the measured powers. Therefore, it is not possible to break down the different loss types of the SRM and its inverter. The simulation of the SRM 
TABLE II

Iron Loss Parameters for Material NO30 [27]

\begin{tabular}{lll}
\hline \hline$k_{1}=2.03 \cdot 10^{-2}$ & $\alpha_{1}=1$ & $\beta_{1}=1.76$ \\
$k_{2}=2.63 \cdot 10^{-5}$ & $\alpha_{2}=2$ & $\beta_{2}=2$ \\
$k_{3}=7.02 \cdot 10^{-6}$ & $\alpha_{3}=1.5$ & $\beta_{3}=1.5$ \\
$k_{4}=4.43 \cdot 10^{-4}$ & $\alpha_{4}=2$ & $\beta_{4}=4.89$ \\
\hline \hline
\end{tabular}

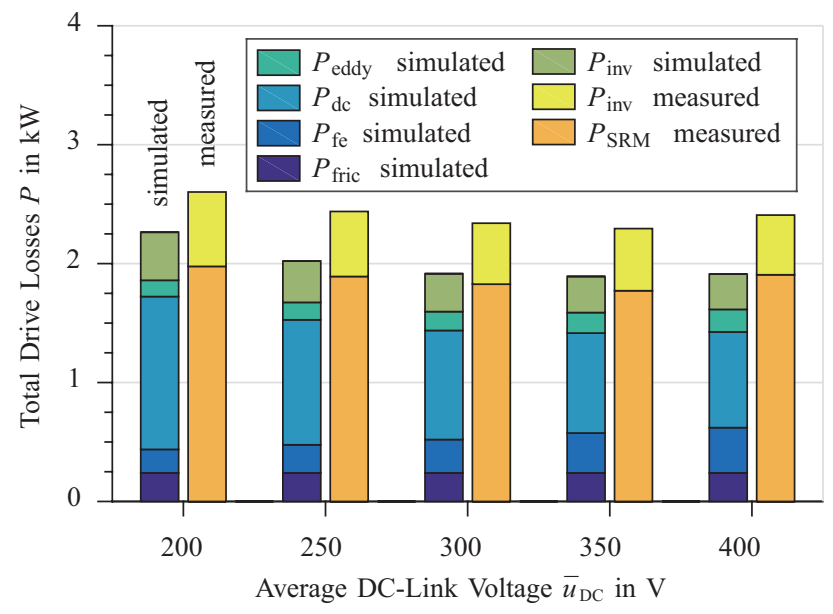

Fig. 12. Influence of different dc-link voltages on SRM losses.

considers copper losses in the windings, including ohmic losses $P_{\mathrm{dc}}$ and eddy current losses $P_{\text {eddy }}$ [26], as well as iron losses $P_{\mathrm{fe}}$ in the rotor and stator. Equation (10) is applied to the simulated flux density of each finite element to determine the specific iron losses $p_{\mathrm{fe}}$ [27], [28]:

$$
p_{\mathrm{fe}}=k_{1} \hat{B}^{\beta_{1}} f^{\alpha_{1}}+k_{2} \hat{B}^{\beta_{2}} f^{\alpha_{2}}+k_{3} \hat{B}^{\beta_{3}} f^{\alpha_{3}}+k_{4} \hat{B}^{\beta_{4}} f^{\alpha_{4}}
$$

The equation is the sum of four Steinmetz terms $k \hat{B}^{\beta} f^{\alpha}$, where $\hat{B}$ is the peak flux density and $f$ is the fundamental frequency of the flux density [29]. The material-specific so-called Steinmetz parameters $k, \alpha$ and $\beta$ are obtained by fitting of loss measurements and given for the used iron sheet material NO30 in Table II. Due to the non-sinusoidal flux waveforms of SRMs, the improved generalized Steinmetz equation (IGSE) [30] is applied to each Steinmetz term. The iron losses $P_{\mathrm{fe}}$ are determined from the specific iron losses $p_{\mathrm{fe}}$ by volume integration and multiplication with the material density as well as the stacking factor of the iron sheets.

Mechanical friction losses $P_{\text {fric }}$ including bearing losses and windage losses due to the double salient structure of the SRM are considered [31], [32]. The losses in the semiconductors of the SRM inverter $P_{\text {inv }}$ are calculated according to the data sheets provided by the manufacturer [21]. Switching and conduction losses in switches and diodes are considered.

The resulting total losses of the SRM and its inverter at a mechanical input power of $-20 \mathrm{~kW}$ and $7500 \mathrm{rpm}$ are shown in Fig. 12. The ohmic copper losses and inverter losses are strongly dependent on the rms current and, therefore, are reduced at higher voltages. The iron losses depend on the peak fluxlinkage and the gradient of the flux linkage $\mathrm{d} \psi / \mathrm{d} t$. According

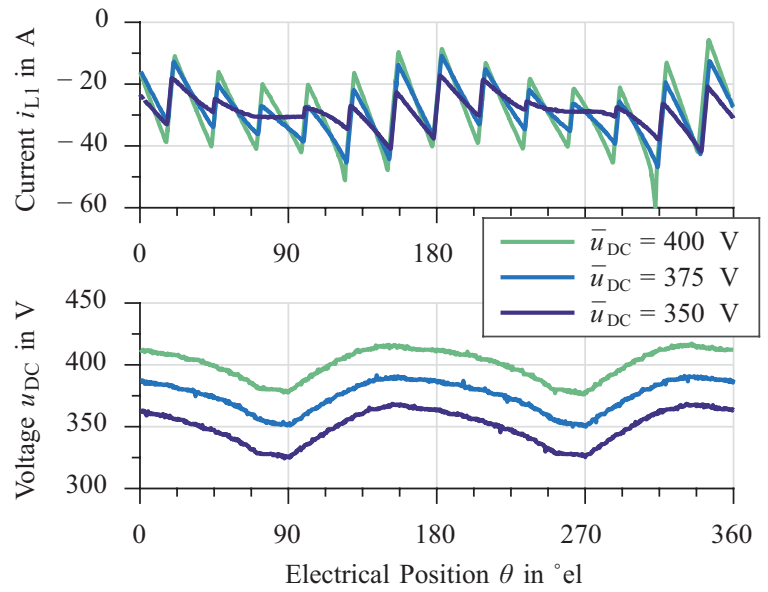

Fig. 13. Measured inductor current and dc-link voltage trajectories for different average dc-link voltages at $u_{\text {bat }}=325 \mathrm{~V}$.

to the observation from Fig. 11, the iron losses increase for increased dc-link voltage level.

Simulation and measurement results show good correlation. The simulated losses are lower for all observed operating points. This might be due to non-simulated effects such as conducting resistance between connections and the thermal dependency of the iron loss parameters. The measurement inaccuracy of the torque sensor is approximately $\pm 25 \mathrm{~W}$ at the rated SRM power [23].

The overall losses decrease with an increasing dc-link voltage level. Between $200 \mathrm{~V}$ and $350 \mathrm{~V}$, the measured efficiency improves from $\eta_{200 \mathrm{~V}}=87 \%$ to $\eta_{350 \mathrm{~V}}=88.5 \%$, i.e., $\Delta \eta \approx 1.5 \%$, and decreases only slightly for $400 \mathrm{~V}$. If only the SRM and its inverter are considered, it is recommended to operate the SRM at a dc-link voltage of $300 \mathrm{~V}$ or higher.

\section{B. Influence of DC-Link Voltage on DC-DC Converter}

Similar to the SRM and its inverter, the efficiency of the dc-dc converter also depends on the choice of the dc-link voltage. As visible in (4), the current through the inductor depends on the input voltage $u_{\text {in }}$ and the difference between input voltage and dc-link voltage $\Delta u=u_{\text {in }}-u_{\mathrm{DC}}$. The measured inductor currents of one-phase $i_{\mathrm{L} 1}$ and dc-link voltages for a battery voltage of $u_{\text {bat }}=325 \mathrm{~V}$ at $-20 \mathrm{~kW}$ and $7500 \mathrm{rpm}$ for different levels of average dc-link voltages are shown in Fig. 13. The PWM current controller with a switching frequency $f_{\mathrm{PWM}}=10 \mathrm{kHz}$ and an average dc-link voltage prediction, as explained in Section II-A, is implemented.

The average inductor current $i_{\mathrm{L} 1}$ is independent of the average dc-link voltage. The current is determined by the battery voltage, the mechanical power of the SRM and the number of dc-dc converter phases. The ripple on the current increases with the voltage difference $\Delta u$ because the gradient $\mathrm{d} i_{\mathrm{L}} / \mathrm{d} t$ during magnetization is proportional to this difference. The gradient of the current during demagnetization is proportional to the input voltage (equation (4)). Hence this gradient is constant for all cases. It can be noted that the inductor saturates around $\left|i_{\mathrm{L}}\right|=45 \mathrm{~A}$. Fig. 13 also shows that 


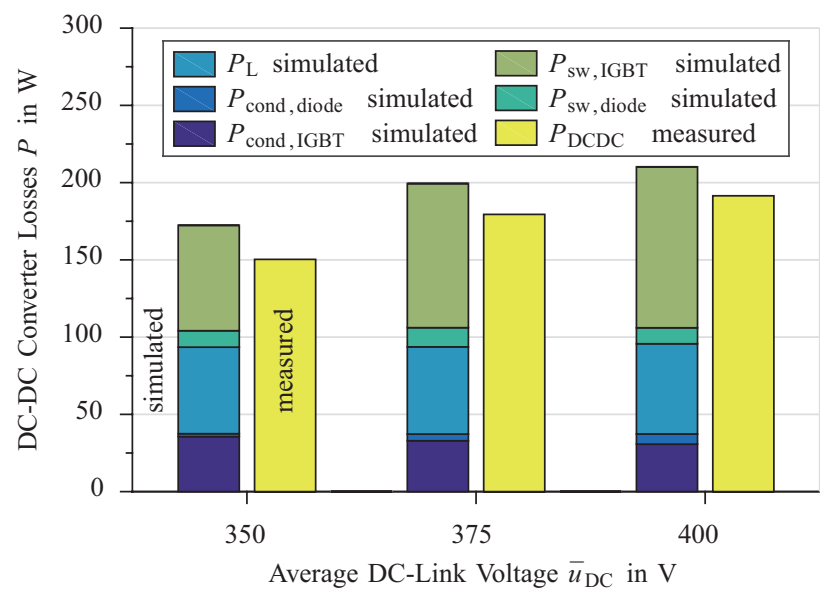

Fig. 14. Losses of dc-dc converter at battery voltage $u_{\text {bat }}=325 \mathrm{~V}$.

the ripple on the dc-link voltage depends on the average dc-link voltage level. The ripple decreases for increased voltage levels.

The resulting simulated inductor losses $P_{\mathrm{L}}$ and the simulated losses in the IGBTs and diodes of the dc-dc converter are depicted in Fig. 14. The semiconductor losses are separated into switching losses $P_{\mathrm{sw}}$ and conduction losses $P_{\text {cond }}$. Again the measurements show only the total dc-dc converter losses $P_{\mathrm{DCDC}}$. Therefore, the simulation results are used to separate the losses by their origin.

The IGBT switching losses depend on the switching frequency, the voltage across the device and the current during turnon and turn-off. The switching frequency is the same for all investigated average dc-link voltage levels. The negative current peaks and the voltage difference between input and dc-link voltage increase for higher average dc-link voltages (Fig. 13). Therefore, the IGBT switching losses increase.

The conduction losses are mainly affected by the rms current through the semiconductors. The duty cycle determines the ratio of the period in which the switch is closed and the current conducted through it. The average absolute duty cycle $|\bar{d}|$ per electrical period decreases with increasing average dc-link voltage. Therefore, depending on the duty cycle, the conduction losses of the IGBTs decrease while the conduction losses of the diode increase with an increasing dc-link voltage. The total semiconductor losses of the dc-dc converter increase with an increasing dc-link voltage.

Similar to the losses in an SRM, the losses occurring in the inductors consist of iron losses and copper losses. The inductors are built with ferrite cores and litz wire. The flux density in the inductor is calculated in an analytical approach. Due to the non-sinusoidal current waveforms, the iGSE is used [30]. Eddy currents are neglected in the copper loss calculation of the windings because high-frequency litz wire is used. For the considered operating points, the copper losses clearly dominate the iron losses. Therefore, the inductor losses increase slightly with the increasing average dc-link voltage as the rms inductor current increases slightly with a higher current ripple.

In conclusion, the losses in the dc-dc converter are mainly determined by the switching losses. The switching losses can be reduced by reducing the switching frequency of the converter

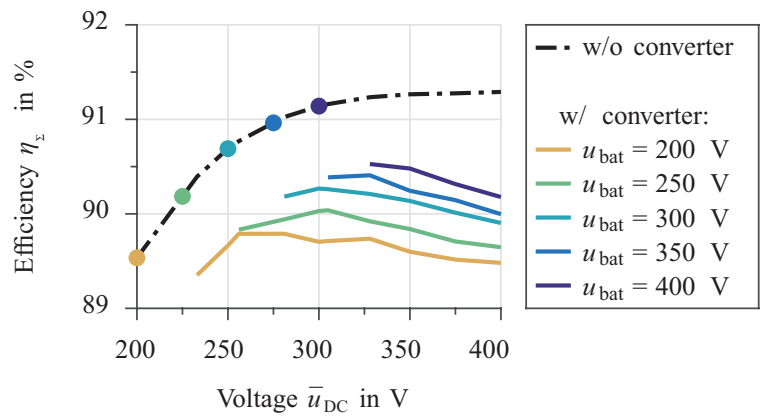

Fig. 15. Simulated total drive efficiency for different battery voltages at mechanical input power $P_{\text {mech }}=-20 \mathrm{~kW}$ and speed $n=7500 \mathrm{rpm}$.

[13]. However, this reduction is limited by the saturation of the inductor at the negative peak current. To increase the current level at which the inductors start to saturate, the magnetic cross section of the core has to be increased. A trade-off between the inductor size and dc-dc converter losses has to be made. As shown in Fig. 14, at a switching frequency of $10 \mathrm{kHz}$, the measured efficiency of the dc-dc converter $\eta_{\mathrm{DCDC}}=P_{\text {el,oul }} / P_{\text {el, in }}$ is above $98.9 \%$ for all operating points.

\section{Total Drive Train Efficiency}

The total drive train efficiency $\eta_{\Sigma}=P_{\text {el,out }} / P_{\text {mech }}$ without a dc-dc converter is shown by the dashed line in Fig. 15. The previously investigated battery voltage levels are marked with dots on this dashed trajectory. In addition, Fig. 15 presents the efficiency of the electric drive train consisting of SRM, machine inverter and dc-dc converter with a reduced dc-link capacitance (solid lines). The presented validation is simulation based to generate a complete efficiency map. The simulation assumes an inductor design which is able to boost the minimum battery voltage of $u_{\text {bat }}=200 \mathrm{~V}$ to the maximum allowed average dc-link voltage of $u_{\mathrm{DC}}=400 \mathrm{~V}$ of the SRM drive train without reaching magnetic saturation. The horizontal gaps between the dots on the dashed line and the starting points of the trajectories with $\mathrm{dc}-\mathrm{dc}$ converter result from the converter control condition $u_{\mathrm{DC}}>u_{\mathrm{in}}$.

For a battery voltage of $u_{\text {bat }}=200 \mathrm{~V}$ and an average dc-link voltage $u_{\mathrm{DC}}$ between $240 \mathrm{~V}$ and $350 \mathrm{~V}$, the losses with the use of a dc-dc converter are lower than the losses without the use of a converter (dot at $200 \mathrm{~V}$ on w/o converter trajectory). Therefore, for this operating points, the dc-dc converter increases the total efficiency of the electric drive train in addition to reducing the size of the dc-link capacitance and the dc-power filtering. For higher battery voltages, the losses with a dc-dc converter are higher than that without a dc-dc converter. In the worst case at $u_{\text {bat }}=300 \mathrm{~V}$, the absolute difference between the efficiency with and without the converter is $\Delta \eta=0.56 \%$ of the absolute mechanical SRM power. Therefore, the total drive train efficiency remains nearly unchanged despite the extra losses in the dc-dc converter.

\section{Transient Behavior of the Active Filter}

To examine the dynamic performance of the dc-dc converter 

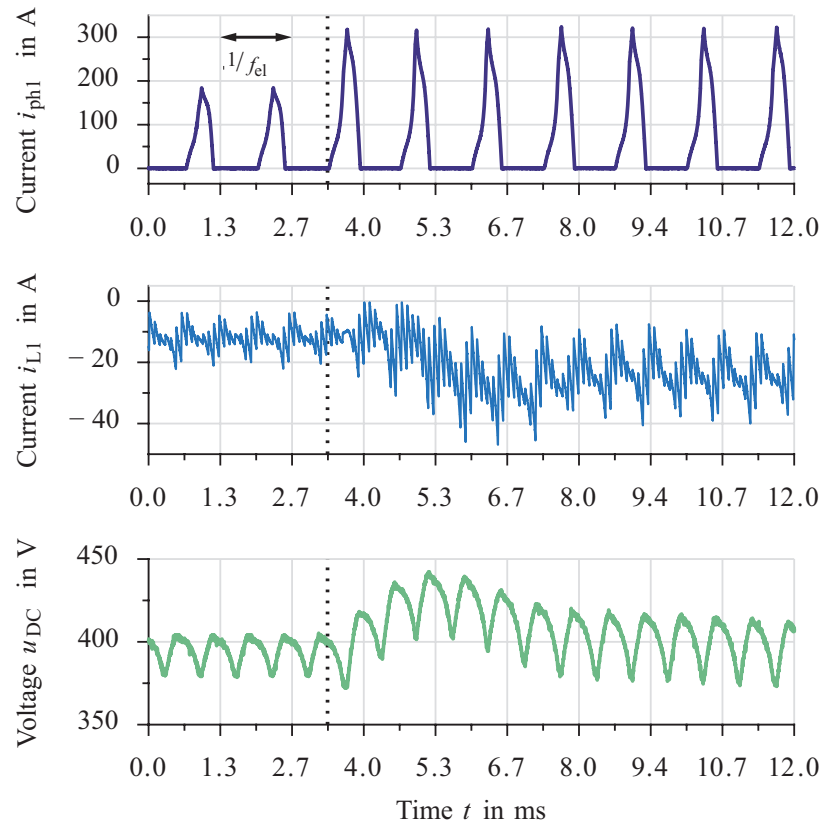

Fig. 16. Measured load step from $P_{\text {mech }}=-10 \mathrm{~kW}$ to $P_{\text {mech }}=-20 \mathrm{~kW}$ at constant speed $n=7500 \mathrm{rpm}, u_{\text {bat }}=375 \mathrm{~V}$ and $\bar{u}_{\mathrm{DC}}^{*}=395 \mathrm{~V}$.

controller, an instantaneous load step of the SRM is investigated. Due to the highly dynamic behavior of an SRM, a load change within one electrical period $1 / f_{\mathrm{el}}$ is feasible. This investigation is a worst case scenario. Indeed, in a range extender application, load ramps over a few seconds are more realistic. Fig. 16 shows the load step response from half rated torque to rated torque after 2.5 electrical SRM periods $(t=3.3 \mathrm{~ms})$. A constant speed is ensured by the load machine of the test bench.

Due to the load step, the average dc-link voltage $\bar{u}_{\mathrm{DC}}$ increases. The PI controller responds to this increase by decreasing the current reference $i_{\mathrm{L}}^{*}$. After approximately $\Delta t=8$ $\mathrm{ms}$ (six electrical SRM periods equal one rotation of the SRM rotor), steady state operation is reached. The experiment proves that the controller of the dc-dc converter is able to respond to highly dynamic load changes.

Fig. 17 presents the transient behavior under motoring operation. In the range extender application, the motoring operation is only used to ramp up the combustion engine. In the first step, the dc-link is precharged to $u_{\mathrm{DC}}=400 \mathrm{~V}$. At $t=10 \mathrm{~ms}$, an constant average torque is applied to ramp up the system from standstill to $n=2000 \mathrm{rpm}$. Due to the low speed, the SRM does not operate in single-pulse operation but in hysteresis current control. For this reason, the dc-link voltage controller operates at a fixed sampling rate instead of the average dc-link voltage. The dc-dc converter operates in DCM due to the lower required power compared to the rated operating point. The validation proves that the controller of the dc-dc converter is capable of handling the dynamic load change of the ramp-up routine.

\section{CONCLUSION}

The investigations in this paper have shown that by using a dc-dc converter, it is possible to actively filter the source current.
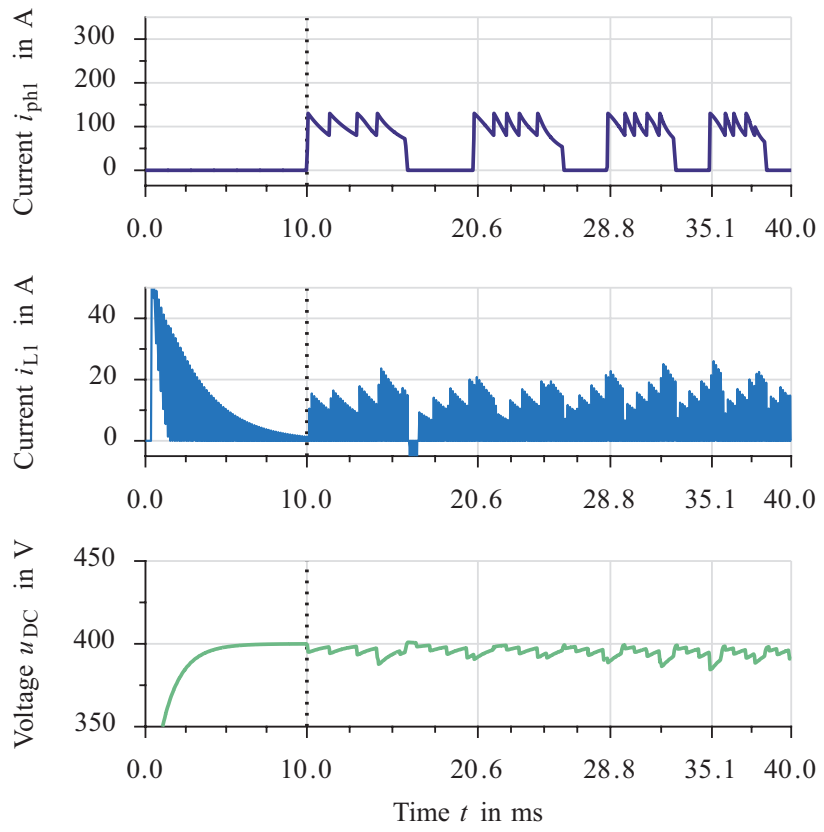

Fig. 17. Simulated ramp-up from $n=0 \mathrm{rpm}$ to $n=2000 \mathrm{rpm}$ at constant average torque $T=6.3 \mathrm{Nm}, u_{\text {bat }}=300 \mathrm{~V}$ and $\bar{u}_{\mathrm{DC}}^{*}=400 \mathrm{~V}$.

With the dc-dc converter, the value of the dc-link capacitor can be reduced by $80 \%$ compared to the state-of-the-art solution. The hardware setup showed that this results in a volume reduction by $60 \%$. Contrary to the behavior of a passive filter, the operating point of the SRM has no effect on the filter quality. Additionally, the investigations have shown that the ability of the dc-dc converter to adjust the dc-link voltage independent of the state of charge of the battery improves the efficiency of the investigated switched reluctance machine and its inverter. The total efficiency of the electric drive train, therefore, remains nearly unchanged despite the extra losses in the dc-dc converter.

\section{ACKNOWLEDGMENT}

The research was funded by the German Federal Ministry of Economic Affairs and Energy (BMWi) within the public project HiREX (FKZ: 01MY14003A). The work was additionally supported by the German Research Foundation (DFG) as part of the post graduate program mobilEM (GRK 1856).

\section{REFERENCES}

[1] C. R. Neuhaus, N. H. Fuengwarodsakul, and R. W. De Doncker, "Control scheme for switched reluctance drives with minimized dc-link capacitance," IEEE Trans. Power Electron., vol. 23, no. 5, pp. 2557-2564, 2007.

[2] C. R. Neuhaus, "Schaltstrategien für geschaltete Reluktanzantriebe mit kleinem Zwischenkreis," Ph.D. dissertation, Shaker Verlag, Aachen, Germany, 2011.

[3] H. Wu, D. Winterborne, M. Ma, V. Pickert, and J. Widmer, "DC link capacitors for traction SRM drives in high temperature automotive environments: A review of current issues and solutions," in Hybrid Elect. Veh. Conf. (2013), pp. 1-6.

[4] R. Inderka, S. von Malottki, C. Nizzola, B. Burkhart, A. Klein-Hessling, and R.W. De Doncker, "Cost efficient switched reluctance generator for range extension unit," in 25th Aachen Colloq. Automobile Engine Technol., 2016, pp. 1-10.

[5] D. Winterborne, M. Ma, H. Wu, V. Pickert, J. Widmer, P. Barrass, and L. 
Shah, "Capacitors for high temperature de link applications in automotive traction drives: Current technology and limitations," in 15th Eur. Conf. Power Electron. Appl. (EPE-ECCE Europe), 2013, pp. 1-7.

[6] W. Suppharangsan and J. Wang, "A new switching technique for dc-link capacitor minimisation in switched reluctance machine drives," in 5th IET Int. Conf. Power Electron., Mach. Drives (PEMD), 2013, pp. 1-6.

[7] W. Suppharangsan and J. Wang, "Experimental validation of a new switching technique for dc-link capacitor minimization in switched reluctance machine drives," in IEEE Int. Elect. Mach. Drives Conf. (IEMDC), 2013, pp. 185-193.

[8] W. Suppharangsan and J. Wang, "Switching technique for minimisation of dc-link capacitance in switched reluctance machine drives," IET Elect. Syst. Transport., vol. 5, no. 4, pp. 2557-2564, 2015.

[9] H.-C. Chang and C.-M. Liaw, "An integrated driving/charging switched reluctance motor drive using three-phase power module," IEEE Trans. Ind. Electron., vol. 58, no. 5, pp. 1863-1775, 2011.

[10] H.-C. Chang and C.-M. Liaw, "On the front-end converter and its control for a battery powered switched-reluctance motor drive," IEEE Trans. Ind. Electron., vol. 23, no. 4, pp. 2143-2156, 2008.

[11] Y. Sun, Y. Liu, M. Su, W. Xiong, and J. Yang, "Review of active power decoupling topologies in single-phase systems," IEEE Trans. Power Electron., vol. 31, no. 7, pp. 4778-4794, 2016.

[12] Advanced Vehicles, Idaho National Laboratory, [Online]. Available: https://avt.inl.gov/vehicle-type/all-powertrain-architecture, Accessed: Feb., 2018.

[13] A. Klein-Hessling, B. Burkhart, and R. W. De Doncker, "Active source current filtering to minimize the DC-link capacitor in switched reluctance drives," in 2nd IEEE Annu. Southern Power Electron. Conf. (SPEC), Dec. 2016, pp. 1-7.

[14] A. Klein-Hessling, B. Burkhart, and R. W. De Doncker, "The effect of excitation angles in single-pulse controlled switched reluctance machines on acoustics and efficiency," in 17th Int. Conf. Elect. Mach. Syst. (ICEMS), 2014, pp. 2661-2666.

[15] Matlab Simulink, MathWorks. [Online]. Available: http://de.mathworks. com/products/simulink/, Accessed: Feb., 2018.

[16] Plecs, Plexim. [Online]. Available: http://www.plexim.com/plecs/, Accessed: Feb., 2018

[17] Flux 2D, CEDRAT. [Online]. Available: http://www.cedrat.com/software/ flux/, Accessed: Feb., 2018.

[18] B. Burkhart, "Switched reluctance generator for range extender applications - Design, control and evaluation," Ph.D. dissertation, RWTH Aachen University, Aachen, Germany, 2018.

[19] B. A. Miwa, D. M. Otten, and M. E. Schlecht, "High efficiency power factor correction using interleaving techniques," in Appl. Power Electron Conf. Expo. (APEC), 1992, pp. 557-568.

[20] Medium Power Film Capacitors, AVX . [Online]. Available: http://www. avx.com/products/film-capacitors/medium-power-film-caps/ ffveffviffweffwi-rohs-compliant/, Accessed: Apr., 2018.

[21] HybridPack 2, FS800R07A2E3, Infineon. [Online]. Available: http:// www.infineon.com/, Accessed: Feb., 2018

[22] B. Burkhart, A. Klein-Hessling, S. A. Hafeez, and R. W. De Doncker, "Influence of freewheeling on single pulse operation of a switched reluctance generator," in 19th Int. Conf. Elect. Mach. Syst. (ICEMS), 2016, pp. 1-6.

[23] Torque meter FLFM1, ATESTEO. [Online]. Available: http://www. atesteo.com/en/testing-equipment/torquemeters/, Accessed: Feb., 2018

[24] Power Analyzer LMG450, ZES Zimmer, [Online]. Available:https://www. zes.com/en/Products/Precision-Power-Analyzers/LMG450, Accessed: Sept., 2018.

[25] Current Transducer LF 2010-S/SPA7, LEM. [Online]. Available: https:// www.lem.com/sites/default/files/products_datasheets/lf_2010-s_spa7.pdf, Accessed: Sept., 2018.

[26] M. Schenk, "Simulative Untersuchung der Wicklungsverluste in Geschalteten Reluktanzmaschinen," Ph.D. dissertation, Shaker Verlag, Aachen, Germany, 2016.

[27] A. Klein-Hessling, B. Burkhart, and R.W. De Doncker, "Iron loss redistribution in switched reluctance machines using bidirectional phase currents," in 8th IET Int. Conf. Power Electron., Mach. Drives (PEMD), 2016.

[28] D. Eggers, S. Steentjes, and K. Hameyer, "Advanced iron-loss estimation for nonlinear material behavior," IEEE Trans. Magn., vol. 48, no. 11, pp. 3012-3024, 2012.
[29] C. P. Steinmetz, "On the law of hysteresis," Trans. Amer. Inst. Elect. Eng., vol. IX, no. 1, pp. 1-64, 1892

[30] K. Venkatachalam, C. R. Sullivan, T. Abdallah, and H. Tacca, "Accurate prediction of ferrite core loss with nonsinusoidal waveforms using only Steinmetz parameters," in IEEE Workshop Comput. Power Electron. Dec. 2016, pp. 36-41.

[31] J. E. Vrancik, "Prediction of windage power loss in alternators," NASA technical note D-4849, Lewis Research Center, Cleveland, USA, 1968.

[32] R. Wrobel, G. Vainel, C. Copeland, T. Duda, D. Staton, and P. H. Mellor, "Investigation of mechanical loss components and heat transfer in an axial-flux PM machine," IEEE Trans. Ind. Appl., vol. 51, no. 4, pp. 3000-3011, 2015

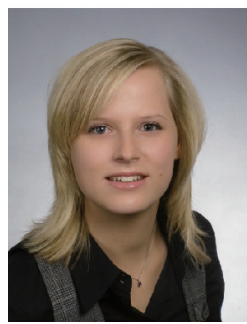

Annegret Klein-Hessling was born in Germany in 1986. She received the Diploma degree in electrical engineering and the Diploma degree in industrial engineering from the RWTH Aachen University, Germany, in 2012. Since October 2012, she has been a research associate at the Institute of Power Electronics and Electrical Drives (ISEA) at the RWTH Aachen University, Germany. Her research interests include the field of switched reluctance drives and their control.

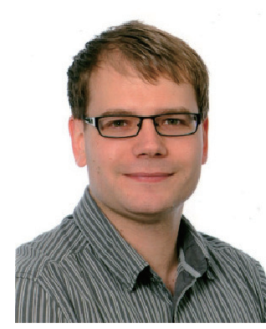

Bernhard Burkhart was born in Germany in 1985. He received the Diploma degree in electrical engineering from the RWTH Aachen University of Aachen, Germany in 2011. Since November 2011, he has been a research associate at the Institute of Power Electronics and Electrical Drives (ISEA) at the RWTH Aachen University, Germany. His research interests include the field of switched reluctance machine design and control, especially for generators.

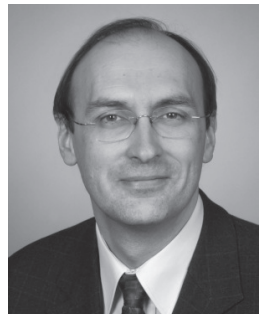

Rik W. De Doncker received the Ph.D. degree in electrical engineering from the Katholieke Universiteit Leuven, Leuven, Belgium, in 1986. In 1987, he was appointed as a Visiting Associate Professor a the University of Wisconsin, Madison. After a short stay as an Adjunct Researcher with Interuniversity Microelectronics Centre, Leuven, he joined, in 1989, the Corporate Research and Development Center, General Electric Company, Schenectady, NY. In 1994, he joined the Silicon Power Corporation, a former division of General Electric Inc., as the Vice President of Technology. In 1996, he became a Professor at the RWTH Aachen University, Aachen, Germany, where he currently leads the Institute for Power Electronics and Electrical Drives. Since 2006, he has been the Director of the E.ON Energy Research Center, RWTH Aachen University. Dr. De Doncker was the President of the IEEE Power Electronics Society (PELS) in 2005 and 2006. He was the founding Chairman of the German IEEE Industry Applications Society PELS Joint Chapter. In 2002, he was the recipient of the IEEE IAS Outstanding Achievement Award. In 2008, he received the IEEE PES Nari Hingorani Custom Power Award. In 2009, he led a VDE/ETG Task Force on Electric Vehicles. In 2010, he received an honorary doctor degree from Riga Technical University, Latvia. In 2013, he received the IEEE William E. Newell Power Electronics Award. 